\title{
The Application and Reflection of PAD in College English Teaching
}

\author{
Jingling Zhang, Peiwei Zheng
}

Department of English Education, Shandong University of Technology, Zibo, China

\begin{abstract}
PAD is the abbreviated form of presentation, assimilation and discussion, which is "The Original Teaching Mode in China". It is mainly a new teaching method proposed in view of the current situation of the classroom in colleges and universities in China. It can improve the teaching effect by enhancing students' learning initiative. Starting with the connotation of PAD, combining the current situation of College English classes and the author's experience, this paper analyses the feasibility of PAD in College English teaching and discusses the existing problems. The author believes that the method provides a new model for college English teaching reform, which is innovative and worth further exploration in practice. It is expected to be more widely used in teaching activities at all levels and disciplines.
\end{abstract}

Keywords-PAD, College English Teaching, Classroom Activities.

\section{INTRODUCTION}

Since 1999, the enrollment scale of colleges and universities has been expanding, and the education of colleges and universities has gradually transformed from "elite education" to "mass education". This change has caused a series of problems, and the quality of classroom teaching in colleges and universities has generally declined. Most schools attach importance to scientific research rather than teaching. As the main teaching backbones of colleges and universities, both young and middle-aged teachers are under great pressure in scientific research tasks and life, and so they often neglect the training of basic teaching skills. As for the students, their learning utilitarian is $m$ is serious, their learning motivation is not strong, the rate of their attendance in class is low, the number of "cellphone addicts" in class increases, and the success of passing examinations becomes the aims of the majority of students. With the development of internet and new media, the drawbacks of traditional classroom teaching are increasingly exposed, and the voice of reform of classroom teaching in colleges and universities is rising. ${ }^{[1]}$

In January 2016, the author first attended the lecture on the PAD teaching method delivered by Zhang Xuexin, Professor of Psychology, Fudan University of Shanghai.
Professor Zhang conducted on-site training of the attendees. Fascinated by the method, the author tried it in the classroom teaching in the spring semester of 2016 so that the atmosphere of classroom teaching changed significantly, the enthusiasm of students to participate was very high, and most students hoped to continue to use this teaching mode. Since it was a trial phase to use the new method, the author's familiarity with the process was not satisfactory, and the students were burdened with the academic tasks, and also some students, especially non-English majors were worried about the delay of their study because of more class discussions, and also were worried about the impact on the test scores and the study of other courses, therefore they showed no great interest in PAD teaching method. The preparatory work they needed to do in advance was only temporarily completed in the discussion class in a hurry. It was difficult to guarantee the quality, the quantity, the effect of class room discussions, and the students' grasp and breakthrough of the key and difficult language points were not satisfactory. Based on these factors, the author had to suspend the teaching mode. Fortunately, after I participated in the training, I ever joined the related communication group. I got the helpful guidance of Professor Zhang Xuexin, the advice from the volunteers of the PAD model and the 
teachers from .other universities. The idea of try ing this innovative teaching mode was always in my heart, so in the next few semesters, I continued to try to use the PAD, though in the actual teaching process there were still such problems, and I constantly encountered some doubts or even blows, I was not discouraged. I persisted in trying the method, constantly reflecting on, adjusting, and eventually I achieved satisfactory results. Now the author will analy ze this kind of teaching method detailedly in the following sections.

\section{BRIEF INTRODUCTION TO CORE IDEA OF "PAD CLASSROOM"}

As we all know, "the core of reform of classroom teaching at university is curriculum reform, and the core of curriculum reform is classroom teaching mode. ${ }^{[2]}$

PAD is a new mode of classroom reform put forward by Professor Zhang Xuexin of Fudan University in view of the main problems existing in the current classrooms in China. It can be called the new wisdom of Chinese education. ${ }^{[3]}$ and is known as "the original teaching mode of China". Its core idea is to allocate half of the classroom time to teachers for teaching, and the other half to students for interactive learning in the form of discussion. The key point in the implementation is to separate the teaching and interactive learning (one week apart), so that students can have sufficient time between the two processes to assimilate knowledge according to their own learning rhythm. In this way, the mode depicts the process of teaching and learning as three processes which are clearly separated in time but interrelated in content: Presentation, Assimilation and Discussion, which can also be referred to as PAD class ${ }^{[4]}$

The connotation of PAD is not to overturn and negate the traditional teaching mode and the later discussion mode, but to integrate the two modes reasonably, giving full play to their respective advantages and making up for their shortcomings at the same time. It emphasizes the interaction between students and students, teachers and students, encouraging autonomous learning. Compared with the traditional teaching mode of lecturing and discussing, the key innovation of PAD lies in staggering the time of lecturing and discussing so that students have time to arrange their study independently after class in order to absorb and assimilate knowledge on their own..

The emphasis on students' independent learning and thinking in PAD is not only conducive to the cultivation of students' autonomous learning ability, but also considerate to the students' individual differences. As a psychological process, an important feature of knowledge internalization is that different students have different internalization speed and modes. Students should have their own learning rhythm to complete the internalization process. Independent learning after class not only gives students time and space to understand the content of the class, but also provides rich content for group discussion in the next class. It can be said that presentation, assimilation and discussion are three interlinked and progressive links, each undertaking different tasks. In addition, in terms of assessment methods, process evaluation is emphasized in the mode, and students' performance and homework completion are included in the assessment scope, so that students can determine their input to the curriculum according to their individual learning objectives, needs and interests.

Since the promotion and practice of PAD in colleges and universities nationwide in 2015, the number of teachers trained offline has reached more than ten thousand. Through the propaganda and exchange of online platforms (QQ group, Wechat group), more college teachers are beginning to understand and practise this teaching method.

\section{PROBLEMS EXISTING IN THE CURRENT COLLEGE ENGLISH CLASSROOMS}

1. Most students do not attach much importance to college English. In many universities, only freshmen and sophomores are taught college English. Some students do not realize that English will bring them more work and life opportunities in the future. After losing the external stimulus of college entrance examination, some students also lose their motivation, interest and enthusiasm in learning English. Even some students are tired of English and think it is a waste of time.

2. Because of the need of employment, some students regard the ultimate goal of learning English at college as passing CET-4 and CET-6 only, thus 
underestimating the cultivation of English application ability and considering vocabulary, grammar and problem-solving skills as the most important ones. ${ }^{[5]}$ As we all know, the teaching goal of College English is to cultivate students' practical language competence. The classroom should be mainly composed of communicative activities. Therefore, students' different expectations of English classroom teaching and actual clas sroom contents make them unwilling to participate in classroom discussion activities. They think that it is a waste of time, or even do not listen to the teachers, mostly they only pay attention to reciting English words with their heads down, or mobile phone games, which leads to the dull atmosphere in the classroom discussions and low enthusiasmfor students to participate in these activities.

3. Communicative Language Teaching (CLT) and Task-based Language Teaching (TLT) both advocate the use of language learning, but in the process of English classroom implementation in China, there is often a lack of discussion. Part of the reason is that Chinese students are influenced by the introverted implicit thought when they were educated young, so they are not as outgoing as European and American students in such public places as classrooms. Another reason is that the objective situation leads to the low level of students' oral English. It is difficult for many students to carry out topic discussion activities. The fact that the ability of students' English oral expression is relatively weak can be said to be one of the most deficient aspects of Chinese students. In the process of discussion, teachers will find that students' language proficiency greatly limits the smooth progress of topic discussion. The purpose of discussion activities is to provide opportunities for students to use English to express their ideas and improve their English proficiency, which can be restricted to situations where they have ideas but can not express them in English. In many cases, they only express their views in Chinese or simply ignore or chat in silence, which makes the meaning of discussion activities meaningless.

\section{RATIONAL ANALYSIS OF THE APPLICATION OF PAD IN COLLEGE ENGLIS H CLASSROOMS}

As a college English teacher, it is necessary for him/her to explore the feasibility of this teaching mode in College English class.

\subsection{Accord with foreign language acquisition theory} and foreign language teaching concept

Over the years, the study of foreign language acquisition and foreign language teaching methods has made a mazing achievements, and the introduction of PAD can be said to be an icing on the cake. This kind of teaching mode conforms to the rule of foreign language acquisition and is also helpful to the implementation of foreign language teaching methods.

Krashen's Affective Filter Hypothes is in the Monitor Hypothesis (1981) points out that learners' emotions have positive or negative effects on learning outcomes.[6] Group discussion can alleviate students' anxiety, it can be carried out in a relaxed and harmonious atmosphere, and also gives full play to students' potential. At the same time, the mutual recognition among group members can also enhance their self-confidence, obtain a sense of pleasure and fullness from activities, and then improve their interest in English learning.

In the traditional teaching mode, the lack of language environment seriously limits the improvement of students' English proficiency, while the PAD teaching mode can increase the contact time between students and the curriculum, and the enthusiasm it arouses will also encourage students to study independently after class, which can improve their learning in itiative. The process of assimilation after class helps students to have enough time to grasp knowledge points and get more useful information, so that they can come prepared to the class, and the discussion in class will no longer feel laborious.

\subsection{Promoting the transformation from passivity to initiative in learning}

In the traditional classroom, students are passively inculcated, while in the PAD class, students are actively engaged in their study. As far as the content of College English teaching is concerned, PAD classes make college students gradually change from passive and mechanical learning to active and happy learning; from skipping class to enjoying class. For example, in the traditional teaching model class, teachers often spend a lot of time explaining 
words, grammar and so on, and students just wait to receive relevant information. However, during a longer time, they will feel dull and boring, and they will only negatively treat the knowledge emphasized by teachers. As a result, even if the teacher is exhausted, the effect is often negligible. Why so? Because in this process, students have been in a passive state, teachers can not stimulate their enthusiasm, let alone develop their potentials. In the PAD class, as contemporary college students, the era of highly developed science and technology can enable them to complete some learning tasks independently, and in this process, everyone will have their own learning experience. In class discussions, members can share their experience from independent learning after class, exchange good learning methods, broaden their knowledge, deepen understanding and form a deep impression. Group members also enhance mutual understanding, promote friendship, and cultivate their teamwork ability.

\subsection{Giving consideration to the realization of teaching objectives and the needs of examinations.}

Limited class time makes students feel that the teaching content in the PAD class may not be helpful for the exam. The traditional English class is based on the purpose of cultivating students' pragmatic competence. And students are still very unfamiliar with the new content, and it is difficult for them to apply it into practice immediately. In addition, the time for preparation is very short, and the students are nervous and insecure, and their preparatory work are time-consuming and laborious. All this will make the discussion difficult to proceed smoothly, leaving the students the impression of a waste of time. As for the PAD mode, students have enough time to understand and master the new content after class. In fact, the classroom can become a place for students to apply the new knowledge they have learned. When they are fully prepared, students will talk and discuss confidently. Effective discussion activities can help improve students' language application ability, achieve teaching objectives, and keep in mind new knowledge. Of course, they can also help to improve test scores and meet the test-oriented psychological needs of students.

\section{THE OPERATING STRENGTHS AND PROBLEMS OF THE PAD TEACHING MODE}

1. Compared with traditional teaching method, teachers using PAD teaching mode do not need to explain language points too systematically, too completely, too comprehensively, too profoundly, too thoroughly, too clearly, too detailed, too vividly, too interestingly and too wonderfully.

2. PAD lectures do not encourage teachers to ask questions and students to respond to them. The reason is that such interaction is inefficient. As teaching time is limited, interaction time will be specially scheduled.

3. The core goal of the present teaching mode is to promote students' autonomous learning after class. Teachers are only guiders and promoters. The whole teaching process of PAD is quite different from the traditional teaching mode. One of the characteristics is that students do not need to do any preparatory work, that is, students are not required to preview.

4. Homework is no longer scored according to right or wrong, but according to completion, attitude and innovation. Teachers' speed of correcting homework has been greatly accelerated, and the burden of correcting homework has been significantly reduced. Teachers no longer correct students' errors in their homework one by one, but put them in group discussions to discover, correct and solve them.

Now, according to my practical experience in the use of PAD method, I will elaborate on the implementation of the method

\section{Liangkaobang（亮考帮) Model}

There is also a new part of the assignment module in the PAD class, which is called "Liangkaobang 亮考帮". In the process of autonomous learning, such as attending class, reading after class, and consulting materials, students should sum up what they feel most deeply, benefit from most and appreciate most, which is called "Liang 亮" ( means glittering). This part is similar to the reflection after reading. In the process of autonomous learning, you understand what you think others may be confused, and express it in the form of questions to 
challenge others, which is called "kao 考"(means to test you). This part is similar to the role as a teacher. Express what you don't know, what you want to know in the form of questions. When discussing, you turn to your fellow students and ask them to help you, which is called "bang 帮(means to help me). It is similar to treating the other members of the group as teachers who can help you solve your confusion. In short, to share personal learning gains is to shine; to challenge your learning opponents is to test you; to help me is to ask for help from those who can. In order to stimulate students to prepare the homework carefully, teachers will tell students in advance that the discussion link will take it as an outline for discussion, which can standardize ideas and improve efficiency, and then register it as the homework. In formative evaluation, it will be used as a scoring basis, directly linked with the usual results, so it will be greatly improved to increase the enthusiasm of students to conscientiously complete the "liangkaobang 亮考帮" part.

The main mode of discussion used in PAD is "interval discussion", that is, the discussion of the contents of the last class proceeds in the present class, which is the core feature of PAD. In the phase of discussion, the teacher does not give any lectures or involves in the discussion activities for the students, but only tours to urge all students to participate seriously. Students can discuss in groups (grouping before class), usually four in a groups during the given time that is usually 15-20 minutes. The discussion mainly centers on the students' learning contents prepared before the class. In order to save time, express ideas clearly and improve the efficiency of discussion, students are allowed to refer to the homework content of "Liangkaobang" which has been prepared. Remind each student to share his or her own experience, harvest and confusion earnestly, answer questions and enlighten each other, note the unsolved problems, and do not allow individual students to dissociate from the group, in a word, everyone has the opportunity to express their ideas. Of course don't forget to require the leader of the group to observe each group member.

At the end of the group discussion, teachers can select three or four groups to make public reports. They can recommend representatives to summarize their ideas on behalf of their group. Teachers can also randomly check students and reproduce the contents of the group discussion. They can spotcheck outstanding students to motivate others. They can also spotcheck students with poor attitudes to warn those who are not active in discussion. Instruct students to ask for help across groups for unsolved problems. If they can't solve the common problems, teachers will organize the whole class to discuss and answer them. Finally, for group and individual performances, teachers make comments and summarize the discussion to ensure the quality of classroom teaching.

\section{Information-based Teaching Platform (duifenyi} 对分易)

The "duifenyi 对分易" teaching platform system is a free network platform specially designed for the teachers who have used PAD classes. It is very convenient for both the computer version and the mobile version. At present, this platform has been extended from the original function of only submitting homework to many functions, such as class management, homework submission, curriculum resources, transcripts and so on. It is more convenient to use, especially the attendance function, which has become a sharp weapon as one of the most important functions for college English teachers to monitor the class attendance .Its use standardizes classroom discipline and helps teachers solve attendance problems that have plagued them for many years. This function can not only use computer scanner to check class, but also rely on Wechat platform to use check-in code to check class. The use of this function helps to increase dramatically the students' attendance rate in English class. This system also has the function of curriculum resources. Teachers upload a large number of relevant curriculum materials to the system. Students can download them at any time and anywhere by themselves, as an extension of extracurricular learning. Especially, the newly developed optimized curriculum function of this system has abundant resources, which can meet various needs of students, such as foreign languages study, personal promotion, certificate examination, workplace skills, etc. This function is favored by students.

Thanks to this platform, teachers can arrange 
homework online and offline. Students can submit homework online. Teachers can download homework online to correct homework, and they can also correct homework online. In today's era when mobile phones are so popular, it becomes very convenient to use mobile phones to correct homework. It is not limited by time and space, and can be operated at any time and anywhere. The function of timely feedback of the results of corrections to every student in the form of Wechat becomes a strong lin $\mathrm{k}$ between teachers and students.

The application of the model of "liangkaobang" and the platform of "duifenyi" makes the teaching mode of PAD more distinctive and becomes a banner of the tide of English classroom teaching reform in colleges and universities in China.

However, in the process of PAD practice, many English teachers also encounter various problems, such as PAD design, operating principles, students' differences, disciplines' differences and so on, which more or less affect the effect of the practice, and even fail to find solutions in time after meeting some difficulties. The enthusiasm of class innovation has been blocked, and eventually it has to return to the traditional teaching mode. The following problems will be faced:

\section{It is difficult to predict the completion of} homework

The comp letion of homework after class is the key to the implementation of the PAD effect. It is not only a test of the mastery of content of classroom teaching, but also provides specific content for classroom discussion to improve classroom efficiency. The theory of Professor Zhang mainly restricts students by scores, but college English for more college students is not a professional course. Students themselves do not attach enough importance to it. Our university values science and technology, and the Academic Affairs Department of our university has a clear stipulation on the proportion of the normal marks in the total scores. Under such circumstances, it is hard to predict whether students can conscientiously complete the assignments after class. For a long time, students have been accustomed to the traditional teaching mode of full classroom instruction and note-taking learning mode. Students follow the teachers passively, they can't actively interact and construct knowledge actively, they have weak learning motivation, and even some students are afraid of English learning. These factors will make some students just copy the answers and can not actively and conscientiously complete their homework.

\section{It is difficult to predict the effect of improving students' language application ability.}

PAD classes may make the classroom lively and encourage students to actively participate in classroom activities, but it faces the same problem with the application of communicative teaching method in English classrooms in China, that is, in the face of a large number of classes, it is difficult for teachers to correct the mistakes made by each student in language application. This will easily lead to repeated mistakes in the future, and may leave a deep-rooted permanent impression in the mind, even to spread errors one after another.

\section{CONCLUSION}

As a new thing, PAD teaching mode can be used in every class, several times in a semester, or even only in individual chapters; it can be used separately, in class, in interval class or in combination of the two, and it is very flexible. The teaching principle of this kind of teaching mode for teachers is to explain intensively and at the same time make room for students to think hard by themselves, without the need for teachers to explain too systematically, too completely, too comprehensively, too profoundly, too clearly, too detailed, too vividly, too interestingly and too wonderfully. The starting point of PAD is to mobilize students' initiative in autonomous learning [7]. It has universal applicability and is suitable for all kinds of disciplines.

As a part of higher education, College English teaching, like many disciplines, has many problems, such as students' academic burnout and inactivity in class. Through the analysis, it can be seen that the theory of PAD teaching mode is helpful to solve many problems existing in the current college English classes, but we can not ignore the more problems that may be encountered in the practical application of the mode in the future. This requires every college English teacher to seriously 
consider how to improve the PAD in practice in order to adapt to the particularity of College English classes, to achieve the teaching objectives of College English, to pool their wisdom, and to find out the best solutions to these problems. We sincerely hope to have more college English teachers and teaching managers concerned who can seriously study and attach importance to this teaching mode, and simultaneously we should further publicize it widely and vigorously advocate the use of the mode. Generally speaking, PAD provides a new way of thinking for the teaching reform of higher education in China, and it is also one of a few operable teaching models in recent years. It is worth further exploration in practice ${ }^{[8]}$

\section{REFERENCES}

[1] Wang Xia. PAD class: A New Exploration of English Reading Teaching. Curriculum Education Research, 2015, (12): 250-260.

[2] Yang Shuping, Wang Dewei and Zhang Lijie. An Analysis of the Classroom-divided Teaching Model and the Role of Teachers and Students. Journal of Liaoning Normal University (Social Sciences Edition), 2015, (2):38.

[3] Zhang Xuexin. PAD Classrooms: New Wisdom of Chinese Education. Science Press, 2016, 11 (1): 1-10.

[4] Zhang Xuexin. PAD Classrooms: A New Exploration of College Classroom Teaching Reform. Fudan Education Forum, 2014, 12 (5): 5-10.

[5] Zhang Nan. How to Improve the Effectiveness of English Classroom Teaching. Overseas English, 2015, (10): 66-67.

[6] Krashen, Stephen D. Second Language Acquisiton and Second Language Learning. Pergamon Press Inc., 1981.

[7] Yang Shuping, Wang Dewei and Zhang Lijie. An analysis of the PAD teaching mode and the roles of teachers and students. Journal of Liaoning Normal University, 2015, 38 (5): 653-658.

[8] Sun Hongye. Feasibility Analysis of the Application of $P A D$ in College English Teaching. Theoretic Observation Serial No. 4, 2016. 